be $\$ 110,000$, but he will not confirm this, saying only that his salary is not all that much higher than it was at Harvard.

The university is also giving him an appointment in astronomy and the chance to hire additional faculty to build up the physics department, which he considers excellent in some areas. "It's a very exciting prospect of being able to build a good group", he says. "I don't believe scientists go anywhere for money."

Deborah Shapley

French nuclear power

\section{Cap de la Hague heads on}

The French government has finally approved a major extension of the nuclear fuel reprocessing plant at Cap de la Hague, near Cherbourg on the English Channel coast. Meanwhile, a major and partly critical report on La Hague and on reprocessing in general remains unpublished.

The extension will cost some FF20,000 million ( $£ 1,786$ million) and covers the upgrading of the existing UP2 400 plant to handle 800 tonnes of spent pressurized water reactor fuel and the construction of a completely new plant (UP3) to handle the same amount. The plants would handle French spent fuel and that arising from plants in Japan, West Germany and Belgium with which the French fuel company Cogema already has contracts. Without the extension, the French nuclear power programme would have been compromised. But UP2 400 has been notoriously ineffective - reprocessing only 250 tonnes in its first five years compared with its projected 2,000. After a series of accidents, one of them potentially disastrous (see Nature 290, 538; 1981), the present government set up a scientific commission to investigate the plant.

The report is now complete and should be published in mid-February - but the government has announced that the expansion of La Hague should go ahead

before the report is out.

The commission's conclusions, although not public, are believed to be broadly in line with remarks communicated by Professor Castaing, its chairman, to science minister Jean-Pierre Chevènement in April. These were that while Cogema and the Commissariat à l'Energie Atomique now "have the knowhow" to build the extension, the technology is only sufficient "for the short and medium term'. Castaing told Chevènement that the most satisfactory solution would be "better waste treatment", in particular the isolation of neptunium and americium from the highlevel waste stream. The chairman also argued that long-term storage of unreprocessed spent fuel, either wet or dry, was feasible, safe and economical, and must be studied because part of the spent fuel to which France is now committed might remain unreprocessed (if there were problems with the new plant for example). The commission also advocated work on final disposal for glassified waste forms and spent fuel itself. And he added that a fast breeder programme "implies substantial progress in reprocessing"' These remarks may have stimulated the government to a preemptive announcement of the La Hague extension.

Robert Walgate

\title{
Martlesham in business
}

An important new semiconductor manufacturing process that was originally developed at British Telecom research laboratories is now being exploited commercially by British Telecom's offshoot, Martlesham Enterprises Ltd, together with Thomas Swan and Co. Ltd.

In January this year British Telecom set up in partnership with other investors to exploit a new process developed by $\mathrm{Dr}$ M.M. Faktor and Dr R.H. Moss at British Telecom's laboratories at Martlesham Heath. The process uses a new series of compounds developed in association with Professor D.C. Bradley at Queen Mary College, London, in a technique known as metallo-organic chemical vapour deposition (MOCVD). Existing techniques for MOCVD which used highly toxic and explosive trialkyl gallium and indium compounds had proved extremely hazardous, and had caused several fires and explosions.

The new chemicals will avoid the use of these dangerous compounds and will also increase the range of applications of the method. In particular the process can now be carried out much more effectively with indium phosphide, a material which is likely to find increasing applications in semiconductor devices which emit and transmit infrared light; connected to optical fibres such devices will be important in long-distance optic information links.

Martlesham Enterprises, after a long search, has now awarded manufacturing and selling rights for the new process to Thomas Swan, a specialist chemical manufacturer, which has already secured advance orders for the new chemicals and process equipment from the Massachusetts Institute of Technology. Tim Beardsley
Soviet science policy

\section{Spread the net}

Softly, softly, decentralization and increased local responsibility are emerging as major themes in President Yuri Andropov's economic policy for the Soviet Union. The annual meeting of the Academy of Sciences of the USSR earlier this month suggested that that decentralization should also apply to science. Matching words to good intentions, coverage of the session in the official party newspaper Pravda concentrated not on the speech of the academy president, Academician Anatolii P. Aleksandrov, but on that of one of the vice-presidents, Vladimir A. Kotel'nikov, which emphasized the role of the "Republic"' academies and the local filials of the All-Union academy.

The occasion coincided with the celebration last week of the $60 \mathrm{th}$ anniversary of the founding of the Soviet

\section{INSERM's new shape}

French medical researchers are to be subjected to a new form of scientific assessment next year - a mixture of stricter and looser rules than those they face at present.

The new arrangements are part of the long-awaited reform of the Institut National de la Santé et de la Recherche Médicale (INSERM), a reform delayed by arguments over whether directors of research groups should have terms limited to 12 years. That question having been settled - the limit will apply, but not immediately - the way was open for official approval of the full reform. That approval has now been granted, and the details of the reform were published last week.

Among the terms are the new forms of scientific assessment, dear to the heart of INSERM's innovatory director-general, M. Philippe Lazar. Lazar has sought a system which would allow non-conformist - and perhaps superficially mediocre - groups to make their mark. He believes talent, particularly in the undervalued sciences, must be given its opportunity, but that judgements, when made, must be strict and scientific.

The reform meets these two objectives. Groups will be judged infrequently (probably less than annually) but firmly by specialist scientific commissions - which must visit the laboratory concerned. The result will be the definition of a research programme, against which the group will be assessed next time round, with a guaranteed long-term budget.

The mechanism will give groups more freedom and more time from pointless form-filling and fund-hunting, Lazar believes. Robert Walgate 
Union as a federal state. (The exact anniversary falls on 30 December.) Formally, Soviet culture is defined as "national in form and socialist in content", although what this means for science is not always easy to say, particularly since the implementation of the "Kruschchev theses" of 1958 which emphasized Russian as the preeminent language of Soviet scientific communication and thus blurred the individuality of such distinctive developments as the "Ukrainian school" of cybernetics of the early 1960s. Some local institutes have, however, achieved international renown, notably the Paton Institute of Electric Welding (Ukraine), the Institute of Astrophysics and Atmosphere Physics (Estonia), the Byurakan Astrophysics Observatory (Armenia), and the Tien Shan Cosmic Ray Station (Kazakhstan). Their reputations, however, derive from their status as representatives of Soviet science rather than of the republic academies to which they belong.

In creating these academies, from the Ukrainian Academy founded in 1919 to the Moldavian in 1961, the Soviet state was following the federal structure of the Soviet Union which formally says that all 15 union republics are fully autonomous. (Significantly, though, the largest republic of all, the Russian Socialist Federative Soviet Republic (RSFSR), has no academy of its own, being presumably well served by the All-Union academy.)

The propaganda value of separate republic academies is clear. In his jubilee speech, Academician Kotel'nikov reiterated the usual half-truth that the Estonian Academy of Sciences was established in 1945, in the process ignoring the 1938 decree of the then independent Estonian Republic setting up that academy.

Recently, there has been an increasing emphasis on the duty of scientific institutes to service local industry. In the remoter areas of the far-flung RSFSR, former research stations have been upgraded into fully-fledged filials of the Soviet Academy of Sciences.

This theme of regional devolution has been evident since before the death of Leonid Brezhnev and the accession of Yuri Andropov as General Secretary of the Party. The media run-up to the jubilee had begun to stress the links between the republic academies and local production. In particular, the influential weekly Literaturnaya Gazeta ran a survey in which the presidents of the 14 republic academies were asked to describe some of the most interesting research carried out by their academies, the main difficulties they encountered and the participation of the academies in the present high-priority food programme. The answers concentrated overwhelmingly on local needs - from the use of lasers for environmental monitoring in Lithuania to soil surveys for new vineyards in Azerbaijan.

Vera Rich

British research policy

\section{Could do much better}

Lack of confidence among would-be innovators was cited last week as a major problem underlying Britain's industrial malaise, by Sir Henry Chilver, chairman of the Advisory Council for Applied Research and Development (ACARD). Sir Henry, who was addressing the Parliamentary and Scientific Committee (an unofficial group of MPs, peers and representatives from industry), stressed the importance of science research and development for Britain, and emphasized the need for effective coordination of policies in the many government departments involved with science and technology.

ACARD's terms of reference were broadened in July and the council is now well placed to play a significant role in coordinating research and development efforts in government and industry. ACARD reports directly to the Prime Minister and will also be advising in the recently announced annual reviews of research expenditure by government departments. Its new role was the result of the government's response to the report on "Science and Government" of the House of Lords Select Committee on Science and Technology, which recommended the appointment of a minister at Cabinet level to speak for science and technology.

Sir Henry pointed out that Britain's expenditure on research and development, while comparable with that of its competitors in terms of percentage of gross domestic product, represented only 7 per cent of the total spent in the five major

industrial nations (see figure). He therefore argued for more spending on research in private industry and a greater concentration of resources in areas with a potential for later exploitation. He also suggested that more ideas from defence research should be taken up.

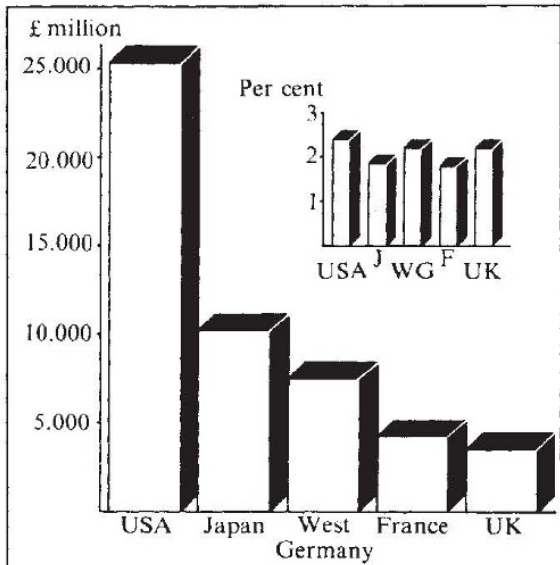

Total and relative expenditure on research and development in the five major industrial nations. Relative expenditure is given as a percentage of gross domestic product.

The primary problem, he said, was one of attitudes, and links between universities and industry should be fostered to encourage academics with good ideas to seek support for commercial development.

Few are likely to disagree, but it is far from certain that university researchers and financial institutions will take notice.

Tim Beardsley

\section{India's second taste of Antarctica}

\section{Lucknow}

The search for a suitable site for a permanent manned research station is the most important task for India's second scientific expedition to Antarctica. Almost exactly a year after the country's first expedition, the 28 -member team set sail on 2 December aboard the hired Norwegian vessel Polar Circle.

As with the first mission, the landing site is to be near an old campsite at $70^{\circ} 3^{\prime} \mathrm{S} / 40^{\circ} 7^{\prime} \mathrm{E}$, named Dakshin Gangotri (Dakshin - south: Gangotri - the source of the River Ganges in the Himalayas). An automatic weather recording station has been operating there for the past year and the team's first task will be to collect a cassette of weather data.

The present expedition - under the leadership of Dr V. K. Raina, a glaciology expert from the Geological Survey of India - is due to stay on the ice for 60 days, compared with the 10 days of the first mission. Intelsat telex and telephone links have been set up to maintain contact with India's National Institute of
Oceanography in Goa and the Department of Ocean Development (DOD) in New Delhi. DOD's link with Antarctica is particularly strong, since the head of the first Antarctic expedition, Dr S. Z. Qasim, is now Secretary of DOD.

With plans to have the permanent base operating by 1985 , and ambitions either to build or to buy a research vessel of its own, India's interest in Antarctica is obviously growing. India has not yet signed the Antarctica Treaty. Prime Minister Indira Gandhi said in Parliament recently that her government is examining the case for signing the treaty, and she stressed that the implications for all developing countries are being considered.

India is taking part in discussions with other developing countries about joint efforts to explore and exploit Antarctica. However, offers of help from the Soviet Union, which offered the use of Soviet airstrips and buildings on the ice cap, have been turned down.

Zaka Imam 